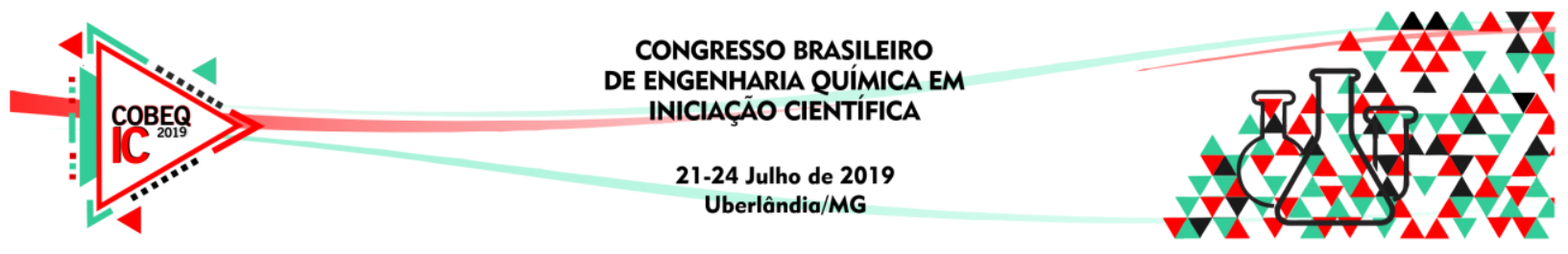

\title{
ESTUDO DA SÍNTESE DA ZEÓLITA ZSM-22 A PARTIR DO MÉTODO DO GEL SECO TIPO TRANSPORTE EM FASE VAPOR
}

\author{
L. P. G. VASCONCELOS ${ }^{1}$, J. R. SANTOS $^{1}$, M. M. URBINA ${ }^{1}$, D. P. S. SILVA ${ }^{1}$, B. J. B. DA \\ SILVA $^{1}$ \\ ${ }^{1}$ Universidade Federal de Alagoas, Centro de Tecnologia \\ E-mail para contato: lary_plentz@hotmail.com
}

\begin{abstract}
RESUMO - A ZSM-22 possui um notável desempenho como catalisador de forma seletiva em reações industriais. Porém, devido à esta apresentar uma fase metaestável, é comum a ocorrência de fases contaminantes ou mesmo a presença de material amorfo em sua estrutura. Neste trabalho foram desenvolvidas duas rotas de síntese a partir do método do gel seco, sendo a primeira a partir do contato do gel seco somente com o vapor de direcionador orgânico e a segunda a partir do contato direto do gel seco com o direcionador. Além da variação do método de síntese, também foram variadas a quantidade de direcionador utilizada (HDMA/SiO ${ }_{2}$ ) e o tempo de cristalização. As amostras foram caracterizadas a de análises de DRX, e a melhor amostra de cada método foi também caracterizada a partir de análises de BET e TPD-NH3. A partir deste trabalho observou-se que a partir o contato direto entre o direcionador orgânico e o gel seco é possível obter a estrutura dessa zeólita com um menor tempo de cristalização, maiores cristalinidades e maiores valores de superfície.
\end{abstract}

\section{INTRODUÇÃO}

Os catalisadores zeolíticos são aluminossilicatos cristalinos que apresentam diferentes estruturas, com tamanhos de poros seletivos a reagentes, compostos intermediários e ainda a produtos, o que permite uma característica de propriedade de seletividade de forma. A estrutura desse material, sua acidez e ainda a capacidade de modificação, permitem que eles sejam bastante utilizados como catalisadores na indústria petroquímica, especificamente, no refino do petróleo (Luna, 2001).

A zeólita ZSM-22 é muito promissora como catalisador seletivo em refinarias de petróleo e indústrias petroquímicas, em processos como isomerização, e reações com olefinas leves (Jamil, 2016). Essa zeólita apresenta uma estrutura que é codificada pela sigla TON, estrutura esta que apresenta um sistema de canais de poros unidimensional compostas por anéis de 10 membros apresentando diâmetros de poro elíptico de $0,46 \times 0,57 \mathrm{~nm}$ e com o tamanho de cristais na gama de 0,5-2 $\mu \mathrm{m}$ (Liu et al., 2015). Esta zeólita apresenta uma estrutura metaestável, por isso é usualmente sintetizada em sistemas apresentando alta agitação para evitar a formação de fases concorrentes na estrutura formada, como é o caso da cristobalita e da ZSM-5, ou até mesmo evitar a formação de material amorfo (Sousa et al., 2014). Outras rotas de síntese vêm sendo estudadas e se mostraram eficientes para a produção 


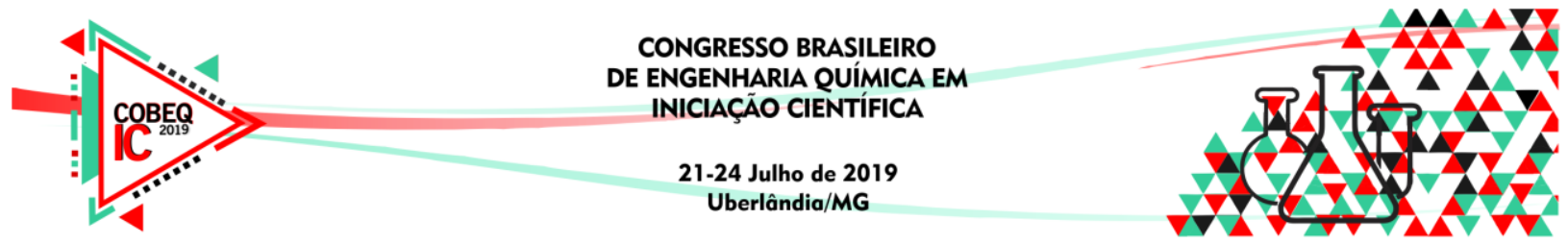

como é o caso da síntese hidrotérmica assistida por micro-ondas, estudada pelos pesquisadores Muraza et al. (2015), a utilização de líquidos iônicos na composição do gel precursor da ZSM-22, como estudado pelos pesquisadores Lopes et al. (2015) e também a partir do método do gel seco, como estudado por Wen et al. (2014).

Dentro deste contexto, esta pesquisa propôs a síntese da ZSM-22 a partir da utilização de dois métodos de síntese: o método 1, que consiste no método de transporte de vapor (VTP) convencional e o método 2, que é uma variação do método VTP convencional e também a partir da variação de alguns parâmetros de síntese, como composição e tempo de cristalização.

\section{METODOLOGIA}

Os reagentes utilizados para a síntese da ZSM-22 foram: sulfato de alumínio (Merck, 51-59\%), súlica coloidal AS-40 (Aldrich, 40\%), hidróxido de potássio (Sigma-Aldrich), diaminohexano (Aldrich, 99\%), água destilada e sementes de cristalização, que foram sintetizadas através do método hidrotérmico, em reator Parr (modelo 4848 Reactor Controller) a $160^{\circ} \mathrm{C}$, utilizando a seguinte composição do gel: $27 \mathrm{HDMA}: 12 \mathrm{~K}_{2} \mathrm{O}: 1,00 \mathrm{Al}_{2} \mathrm{O}_{3}$ : $90 \mathrm{SiO}_{2}$ : $3600 \mathrm{H}_{2} \mathrm{O}$.

\subsection{Síntese das Amostras da ZSM-22}

As amostras de ZSM-22 foram sintetizadas a partir da variação da razão $\mathrm{HDMA} / \mathrm{SiO}_{2}$ $(0,15 ; 0,3$ e 0,6$)$, tempo de cristalização (24-48 horas) e do método de síntese utilizado, sendo então gerado o planejamento experimental apresentando 12 sínteses que foram realizadas conforme a Tabela 1.

Tabela 1 - Planejamento experimental das sínteses

\begin{tabular}{|c|c|c|c|c|c|c|c|}
\hline Método & \multirow{2}{*}{$\begin{array}{c}\text { Código da } \\
\text { síntese }\end{array}$} & \multicolumn{6}{|c|}{ Composição do gel } \\
\cline { 3 - 8 } & & $\mathrm{SiO}_{2} / \mathrm{Al}_{2} \mathrm{O}_{3}$ & $\mathrm{OH}^{-} / \mathrm{SiO}_{2}$ & $\mathrm{HDMA} / \mathrm{SiO}_{2}$ & $\mathrm{H}_{2} \mathrm{O} / \mathrm{SiO}_{2}$ & Temp. $\left({ }^{\circ} \mathrm{C}\right)$ & $\begin{array}{c}\text { Sementes } \\
(\%)\end{array}$ \\
\hline 1 & $\mathrm{Z} 1$ & 90 & 0,1 & 0,15 & 40 & 140 & 10 \\
\hline 1 & $\mathrm{Z} 2$ & 90 & 0,1 & 0,3 & 40 & 140 & 10 \\
\hline 1 & $\mathrm{Z} 3$ & 90 & 0,1 & 0,6 & 40 & 140 & 10 \\
\hline 2 & $\mathrm{Z} 4$ & 90 & 0,1 & 0,15 & 40 & 140 & 10 \\
\hline 2 & $\mathrm{Z} 5$ & 90 & 0,1 & 0,3 & 40 & 140 & 10 \\
\hline 2 & $\mathrm{Z} 6$ & 90 & 0,1 & 0,6 & 40 & 140 & 10 \\
\hline
\end{tabular}

Para o preparo do gel seco, os reagentes foram inicialmente dissolvidos em água destilada e adicionados a um béquer que permaneceu em agitação através de um agitador mecânico até a sua homogeneização, esse processo durou em torno de 60 minutos. Em seguida, esse gel precursor foi submetido a um processo de secagem em uma estufa a uma temperatura de $60{ }^{\circ} \mathrm{C}$. Após o gel estar seco, este foi moído através de um moinho modelo IKA A11 basic.

Terminada a moagem, no método VTP convencional (método 1), o sólido resultante foi então inserido em copos de teflon pequenos, suportados em um copo de teflon maior contendo água destilada e direcionador orgânico no fundo, já no método VTP com variação (método 2) o sólido foi inserido nos copos de teflon pequenos em contato direto com o 


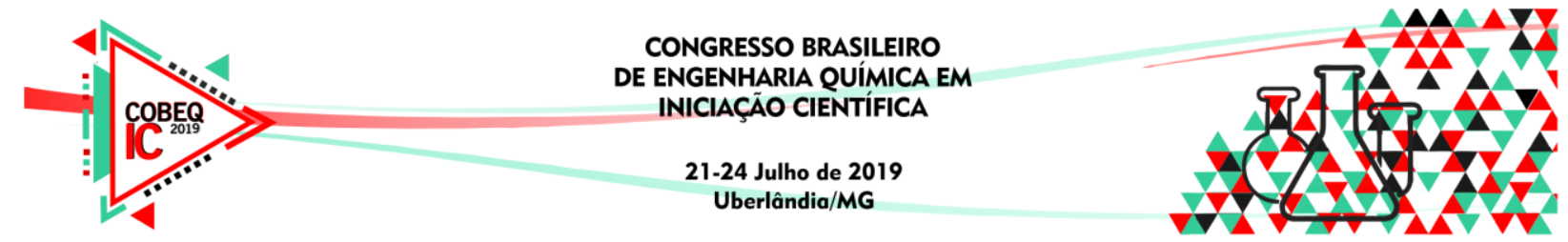

direcionador orgânico e no copo de teflon maior continha apenas água destilada. Por fim os copos de teflon maiores foram inseridos em autoclaves e inseridos na estufa à $140{ }^{\circ} \mathrm{C}$. Nos tempos pré-determinados, os autoclaves foram resfriadas até temperatura ambiente. $\mathrm{O}$ sólido resultante do processo de cristalização foi lavado com água destilada a partir de filtração à vácuo até que apresentar um $\mathrm{pH}$ neutro em seguida o sólido foi inserido em uma estufa a 100 ${ }^{\circ} \mathrm{C}$ durante 24 horas até que este estivesse seco.

\subsection{Caracterizações}

Terminada a síntese das amostras, foi realizada a caracterização das amostras a partir das análises de DRX, BET e TPD-NH $\mathrm{NH}_{3}$. Os difratogramas obtidos a partir das análises de DRX foram analisados em comparação com o difratograma padrão encontrado no banco de dados da International Zeolite Association (IZA) para a estrutura TON conforme a Figura 1.

Figura 1 - Difratograma comparativo da ZSM-22

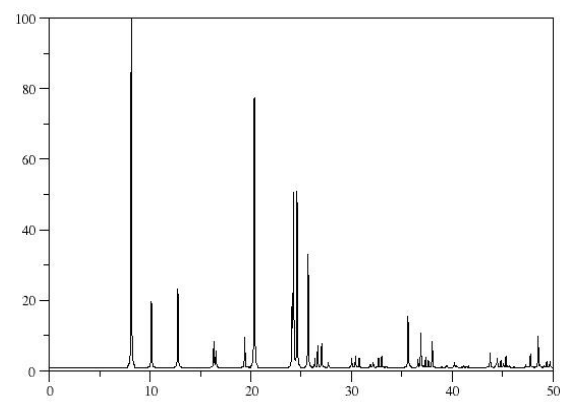

Os principais picos analisados para a formação da estrutura TON referente à ZSM-22 estão compreendidos aproximadamente em $18,5-19,5^{\circ}, 20-21^{\circ}, 23-25^{\circ}$ e $25,1-26,1^{\circ}$ graus $2 \theta$. A amostra que apresentou um maior somatório das áreas dos picos, foi considerada a amostra com $100 \%$ de cristalinidade, enquanto a cristalinidade das outras amostras foram calculadas em comparação com a amostra $100 \%$. As demais caracterizações foram realizadas apenas para a melhor amostra de cada método.

\section{RESULTADOS E DISCUSSÕES}

A Figura 2 mostra os difratogramas comparativos das sínteses realizadas a partir dos dois métodos. Para as amostras sintetizadas pelo método 1 pode-se observar que as amostras com 24 horas de cristalização apresentam uma mistura de fase amorfa com picos característicos da ZSM-22 e que com o passar do tempo a intensidade dos picos das amostras foi aumentando. Já para as amostras sintetizadas pelo método 2 observa-se que as amostras com 24 horas de cristalização não apresentam mais parte amorfa e as amostras já estão totalmente cristalizadas, com o passar do tempo a intensidade dos picos das amostras também foram aumentando, porém ao se utilizar uma maior quantidade de direcionador foi observado a presença de picos contaminantes das estruturas da cristobalita e da ZSM-5. Comparando-se as amostras dos dois métodos, pode-se observar que o contato direto do direcionador orgânico com o gel seco aumenta a velocidade de formação da estrutura da ZSM-22, e que com a utilização de uma grande quantidade de direcionador, este fato pode ocasionar na formação de estruturas contaminantes. 


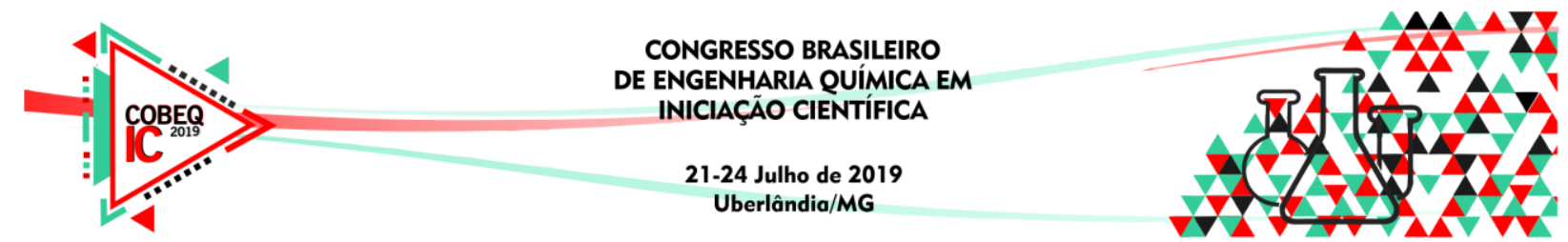

Figura 2 - Difratograma comparativo das amostras da ZSM-22. (*) pico característico da cristobalita; (\# pico característico da ZSM-5).
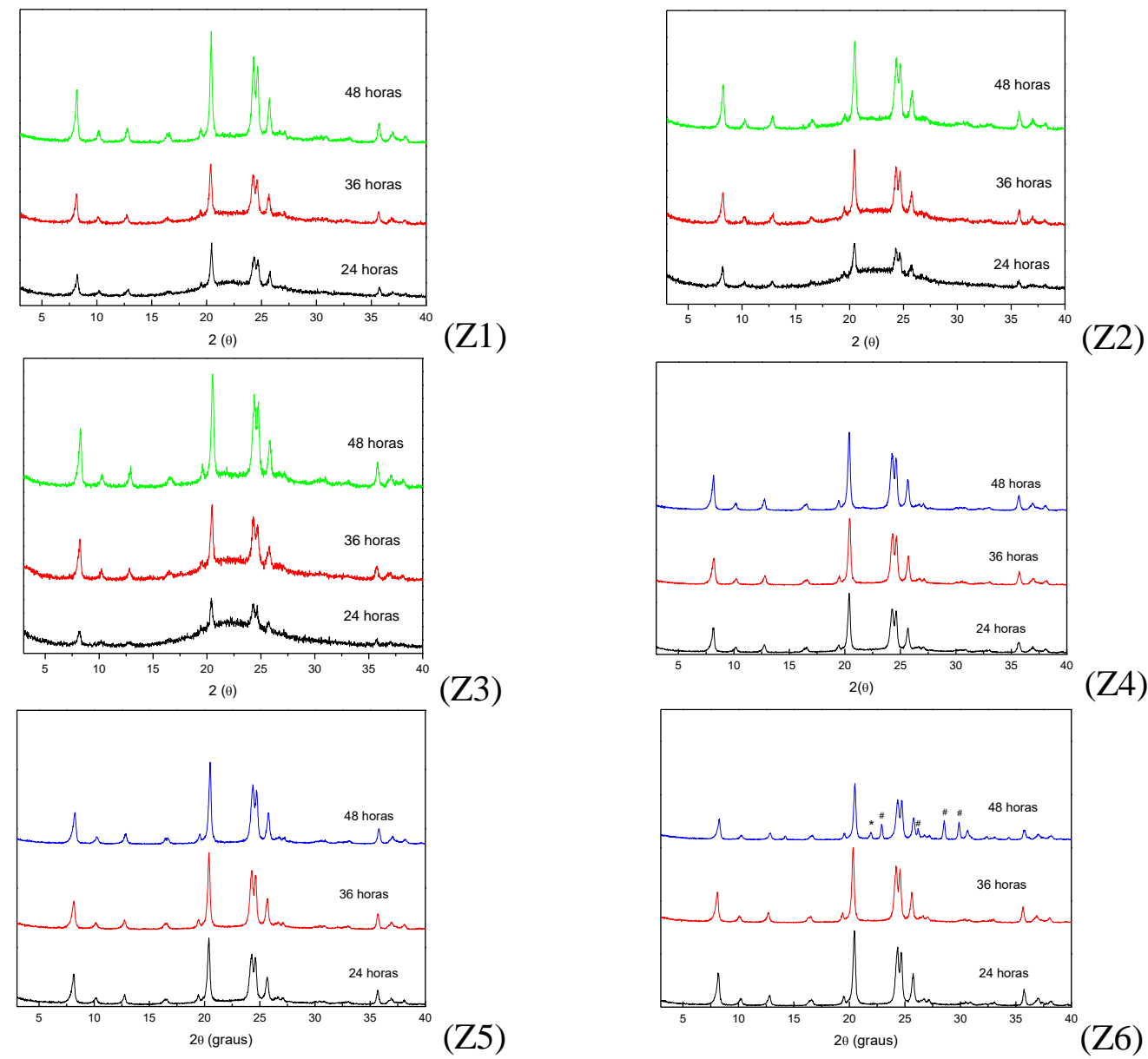

A partir dos difratogramas das amostras, foram então calculadas as cristalinidades relativas das amostras, sendo a amostra da síntese $\mathrm{Z1}$ com 48 horas de cristalização considerada a melhor amostra sintetizada pelo método 1, e a Z4 com 48 horas foi considerada a melhor amostra pelo método 2, tendo em vista que estas apresentaram uma maior cristalinidade em relação às outras amostras de seus respectivos métodos de síntese. A cristalinidade das melhores amostras de cada síntese encontra-se na Tabela 2.

Tabela 2 - Cristalinidade da melhor amostra de cada síntese

\begin{tabular}{|c|c|c|c|c|c|c|}
\hline Síntese & Z1 & Z2 & Z3 & Z4 & Z5 & Z6 \\
\hline $\begin{array}{c}\text { Tempo de } \\
\text { cristalização } \\
\text { (horas) }\end{array}$ & 48 & 72 & 48 & 48 & 48 & 36 \\
\hline $\begin{array}{c}\text { Cristalinidade } \\
(\%)\end{array}$ & 30 & 23 & 23 & 100 & 91 & 98 \\
\hline
\end{tabular}

Na Figura 3 encontra-se o gráfico referente à análise de BET das amostras Z1 e Z4 com 48 horas de cristalização, observando que as amostras apresentaram curvas de adsorção do 


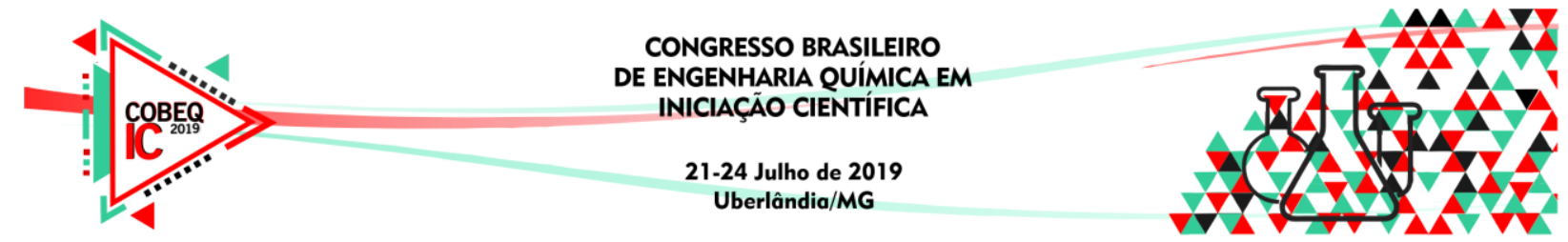

tipo (I), que é característica de materiais microporosos. A partir dos dados fornecidos pela análise foi então construída a Tabela 3, podendo-se observar a partir dela que o contato direto entre o direcionador orgânico e o gel seco favoreceu a síntese de uma estrutura com maiores valores de área e volume superficial. Este fato pode ser explicado pelo fato de como o direcionador orgânico está mais próximo ao gel seco no método 2, este pôde ser melhor incorporado na estrutura do material, acarretando em amostras com maiores áreas e volumes de poro e consequentemente maior área superficial.

Figura 3 - BET Z1 e Z4 com 48 horas de cristalização.
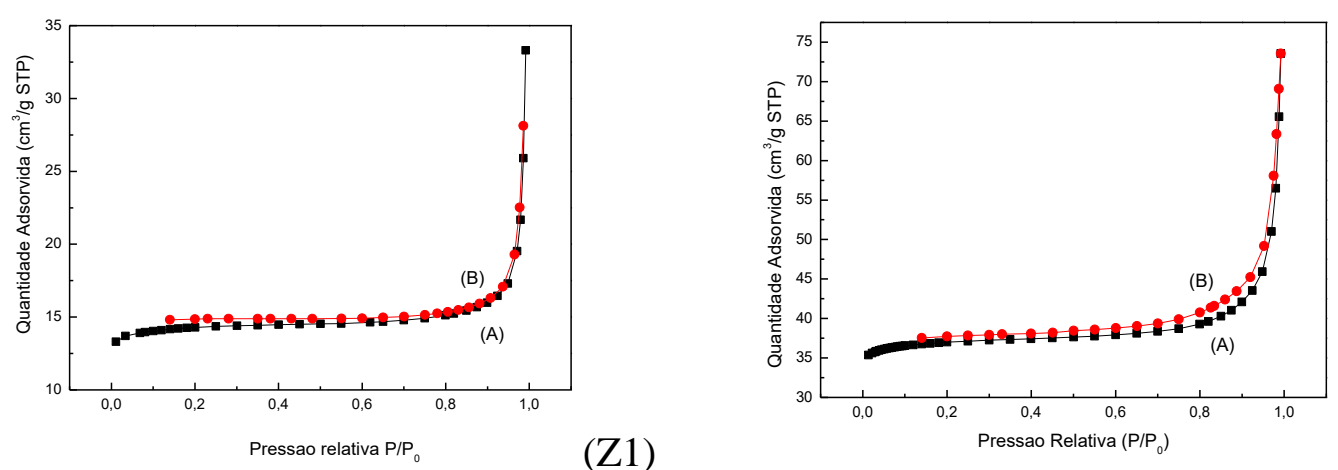

(Z4)

Tabela 2 - Cristalinidade da melhor amostra de cada síntese

\begin{tabular}{|c|c|c|c|c|}
\hline Síntese & $\begin{array}{c}\text { Área superficial } \\
\text { específica } \\
\left(\mathrm{m}^{2} / \mathrm{g}\right)\end{array}$ & $\begin{array}{c}\text { Área da } \\
\text { superfície } \\
\text { externa }\left(\mathrm{m}^{2} / \mathrm{g}\right)\end{array}$ & $\begin{array}{c}\text { Área de } \\
\text { microporos } \\
\left(\mathrm{m}^{2} / \mathrm{g}\right)\end{array}$ & $\begin{array}{c}\text { Volume de } \\
\text { microporos } \\
\left(\mathrm{cm}^{3} / \mathrm{g}\right)\end{array}$ \\
\hline \hline $\mathrm{Z} 1$ & 48 & 5 & 43 & 0,0198 \\
\hline $\mathrm{Z} 4$ & 141 & 9 & 132 & 0,0533 \\
\hline
\end{tabular}

Na Figura 4 encontra-se o gráfico referente à análise de TPD-NH 3 das amostras Z1 e Z4 com 48 horas de cristalização, observando que ambas as amostras apresentaram dois picos de acidez, sendo o primeiro característico de sítios ácidos fracos e o segundo de sítios ácidos moderados e fortes, observa-se também que o sinal da amostra Z4 apresenta mais ruídos do que o sinal da amostra $\mathrm{Z1}$, isto pode ser devido a algum distúrbio no equipamento utilizado. $\mathrm{Na}$ Figura 4 também se encontra os valores da acidez de Bronsted característica dos sítios ácidos fracos e a acidez de Lewis, característica dos sítios ácidos fortes das amostras. Pode-se observar que a amostra Z1 apresenta uma maior quantidade de sítios do que a amostra Z4.

Figura 4 - TPD-NH 3 Z1 e Z4 com 48 horas de cristalização. 

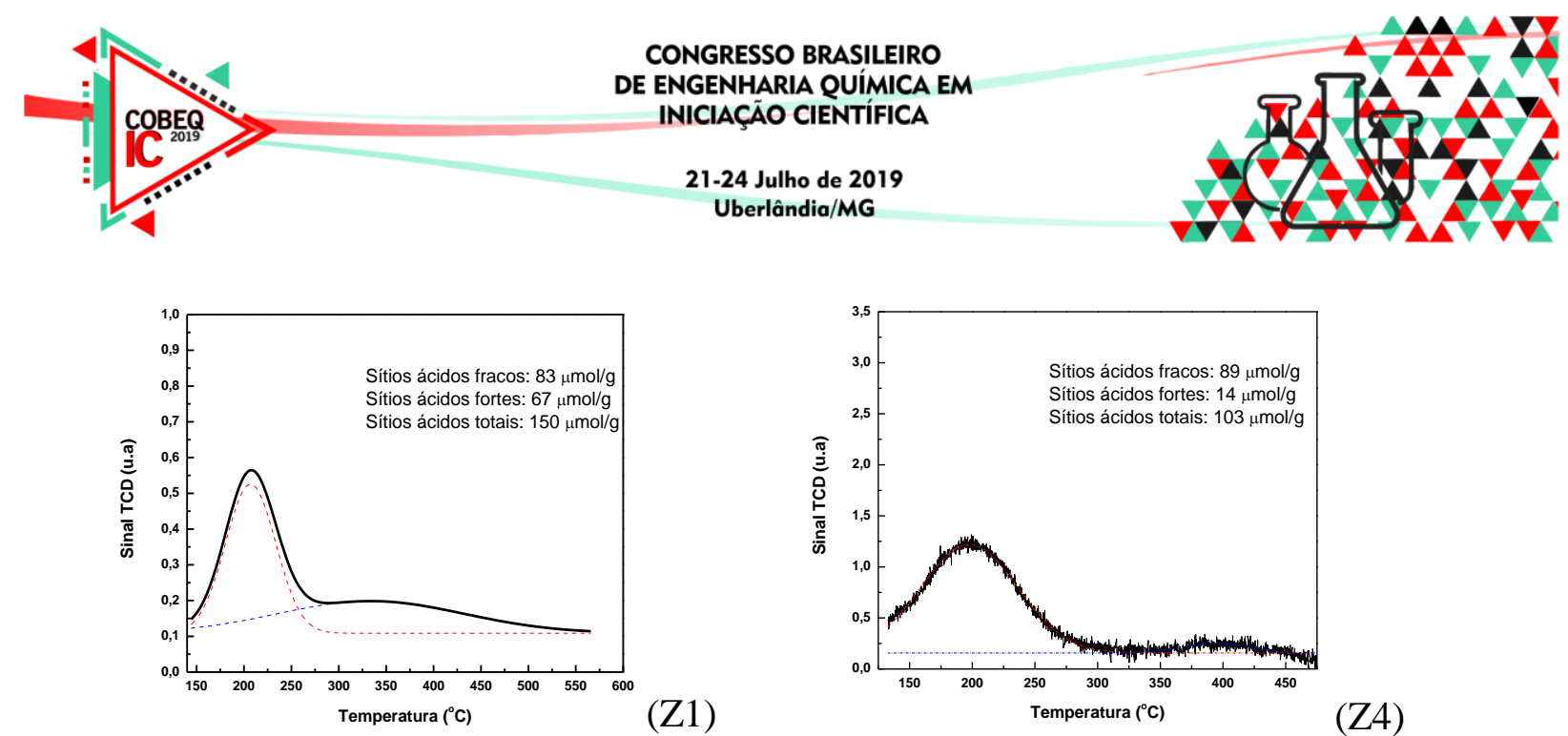

(Z4)

\section{CONCLUSÕES}

A partir deste trabalho foi possível concluir que a zeólita ZSM-22 pode ser sintetizada em sua forma pura e cristalina a partir do método VTP convencional (método 1) e do método VTP com variações (método 2). Porém, a partir do método 2, é possível sintetizar essa zeólita com menos tempo de cristalização, com uma maior intensidade de picos e com maiores valores de áreas e volumes superficiais, porém ao se utilizar uma maior quantidade de direcionador orgânico, as amostras com maiores tempos de cristalinidade apresentam picos de estruturas contaminantes. Já as amostras sintetizadas a partir do método 1 apresentaram maiores valores de acidez do que as amostras sintetizadas pelo método 2 .

\section{REFERÊNCIAS}

JAMIL, A. K., MURAZA, O.; Facile Control of Nanosized ZSM-22 Crystals Using Dynamic Crystallization Technique; Microporous and Mesoporous Materials, v. 227; p. 16-22; 2016.

LIU, S., REN, J., ZHU, S., ZHANG, H., LV, E., XU, J., LI, Y. W.; Synthesis and Characterization of the Fe-Substituted ZSM-22 Zeolite Catalyst with High n-Dodecane Isomerization Performance; Journal of Catalysis; v. 330; p. 485-496; 2015.

LOPES, C. W., FINGER, P. H., MIGNONI, M. L., EMMERICH, D. J., MENDES, F. M. T., AMORIM, S., PERGHER, S. B.C.;TiO2-TON Zeolite Synthesis Using an Ionic Liquid as a Structure-Directing Agent; Microporous and Mesoporous Materials; v. 213; p. 78$84 ; 2015$.

LUNA, F. J.,SCHUCHARDT, U.; Modificação de Zeólitas para uso em Catálise; Química Nova; v. 24, p. 885-892; 2001.

MURAZA, O., LATEEF, A. A., TAGO, T., NANDIYANTO, A. B. D., KONNO, H., NAKASAKA, Y., YAMANI, Z. H., MASUDA, T.; Microwave-Assisted Hydrothermal Synthesis of Submicron ZSM-22 Zeolites and their Applications in Light Olefin Production; Microporous and Mesoporous Materials; v. 206; p. 136-143; 2015.

WEN, H., ZHOU, Y., XIE, J., LONG, Z., ZHANG, W., WANG, J.; Pure-silica ZSM-22 Zeolite Rapidly Synthesized by Novel Ionic Liquid-Directed dry-gel Conversion; Royal Society of Chemistry; v. 4; p. 49647-49654; 2014. 